\title{
Heterogeneous Nonmarket Benefits of Managing White Pine Blister Rust in High-Elevation Pine Forests
}

\author{
NOTE: THIS ACCEPTED MANUSCRIPT HAS NOT BEEN EDITED. PLEASE REFER TO, AND CITE, THE \\ PUBLISHED JOURNAL ARTICLE VERSION OF THIS WORK:
}

Meldrum, J. R., Champ, P. A., Bond, C. A. 2013. Heterogeneous nonmarket benefits of managing white pine bluster rust in high-elevation pine forests. Journal of Forest Economics 19:61-77. doi: 10.1016/j.jfe.2012.10.001.

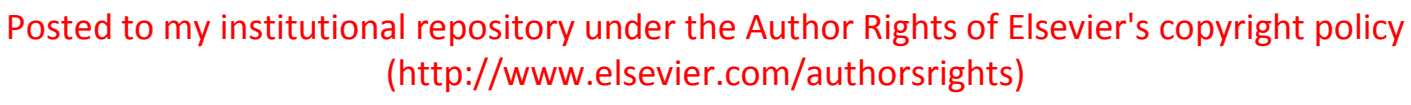

\begin{abstract}
:
This article describes a nonmarket valuation study about benefits of managing the invasive disease white pine blister rust in high-elevation forests in the Western United States. Results demonstrate that, on average, households in the Western United States are willing to pay \$154 to improve the resiliency of these forests. Factor analysis shows that long-run protection of the forests dominates recreation in motivating support. Cluster analysis suggests three groups of survey respondents: those indifferent to the program and not willing to pay, those wanting to protect the future of the high-elevation forests, and those wanting to protect both the forests and related recreational opportunities.
\end{abstract}

\section{Keywords:}

invasive species management; attitudes; nonmarket valuation; contingent valuation; cluster analysis; factor analysis

\section{Authors:}

James R. Meldrum*; Institute of Behavioral Science, University of Colorado, Boulder, CO

Patricia A. Champ; USDA Forest Service, Rocky Mountain Research Station, Fort Collins, CO

Craig A. Bond; Department of Agricultural and Resource Economics, Colorado State University, Fort Collins, CO

\section{Acknowledgements:}

We would like to thank our funding sources, including the USDA-PREISM grant program, USDA Forest Service Rocky Mountain Research Station, and the Colorado Agricultural Experiment Station, as well as participants at the 2010 CU Environmental and Resource Economics workshop and the 2010 CU Environmental Studies Graduate Student Seminar Series for constructive comments. 


\section{Introduction}

As the rate and extent of global travel and trade has increased over the past century, so too has the threat posed by non-native species to the ecological sustainability of many forested ecosystems (Holmes et al. 2009; Liebhold et al. 1995). Each year, invading alien species cause approximately $\$ 120$ billion in costs and losses to agriculture, forestry, and public health in the United States, $\$ 4.2$ billion of which is due to losses in timber value alone (Pimentel et al. 2005). Nonmarket impacts, not included in these estimates, are likely even greater (Holmes et al. 2008, 2009; Kramer et al. 2003; Rosenberger et al. 2012, Appendix C). Though these losses clearly are substantial, resources for managing forests are constrained, and government agencies carefully weigh whether the benefits of potential management options justify the costs. For example, in response to a variety of threats to whitebark pines, the Natural Resources Defense Council recently petitioned to have the species listed under the protection of the Endangered Species Act. The U.S. Fish and Wildlife Service reviewed the case and announced that although "there is sufficient scientific and commercial data to propose listing throughout its range," it will devote its resources to other priorities at this time (U.S. Fish and Wildlife Service 2011). Another important consideration when weighing forest management options is public acceptance.

One of the most serious threats facing the whitebark pine is the disease white pine blister rust (WPBR). This disease is caused by the non-native fungus Cronartium ribicola, which threatens the high-elevation white pine species collectively known as five-needle pines. The fungus was introduced to Vancouver, Canada, in the early 20th century and now has spread across much of the natural range of high-elevation forests in Western North America (Burns et al. 2008; Liebhold et al. 1995). These forests include some of the oldest living organisms on Earth and are associated with many important ecosystem services, including wildlife habitat, 
watershed regulation, and recreational opportunities (Mattson et al. 1992; Petit 2007; Robbins 2010; Samman et al. 2003; Tomback and Kendall 2001; U.S. Fish and Wildlife Service 2011). Though mountain pine and other bark beetle outbreaks have received substantially more press in recent years in the Western United States, WPBR has the potential to be more damaging to the long-run health of high-elevation forests. The disease impairs a forest's natural ability to recover from disturbances, including the native beetle outbreaks. It degrades forest resiliency by attacking white pines at all life-cycle stages (Burns et al. 2008; Logan and Powell 2001). Further, the fungus likely will continue to spread regardless of attempts at either eradication or containment, due to a complex lifecycle involving multiple hosts and airborne dispersal (Liebhold et al. 1995; Maloy 1997). The slow growing cycles of high-elevation white pines mean that the chances of success for any potential treatment plans will not be known for many years (Burns et al. 2008; Schoettle and Sniezko 2007). However, treatments focused on increasing the frequency of genetic rust resistance across the high-elevation forests' range show promise for improving the forests' resiliency to the disease (Bond et al. 2011; Burns et al. 2008; Kinloch 2003; Samman et al. 2003; Schoettle and Sniezko 2007; Schwandt 2006).

Thus, government agencies recognize the problems facing high-elevation white pine forests, and knowledge about treatment options exists. However, proposed resilience-based treatments for WPBR are costly (Burns et al. 2008; Schoettle and Sniezko 2007), and as with many invasive species issues (Holmes et al. 2008), there is little understanding of the social benefits of such treatments. Though many aspects of market and nonmarket values related to managing forests have been studied extensively (see Sills and Abt (2003) and Barrio and Loureiro (2010) for a broad introduction), a gap remains in the literature for information directly pertinent to the context of WPBR management in nontimber forests. Specifically, although 
numerous valuation studies over the past few decades have addressed the nonmarket values related to managing forest pests, including several studies pertaining to invasive insects (e.g., Haefele et al. 1992; Holmes and Kramer 1996; Jakus and Smith 1992; Miller and Lindsay 1993; Moore et al. 2011), very few studies address the effects of forest diseases or pathogens.

This study fills that gap, using contingent valuation (CV) to estimate the public benefits of managing the invasive species causing WPBR in high-elevation five-needle pine forests. As such, it presents the first nonmarket valuation of the benefits of managing a forest invasive fungus, and the first nonmarket valuation of managing a forest invasive species in the Western United States. Recent research (e.g., Bestard and Font 2010; Hynes et al. 2011) recognizes that $\mathrm{CV}$, rather than attribute-based choice experiment approaches, is more appropriate for holistically valuing a policy, particularly when the policy will be implemented across a large spatial scale. In addition, the CV methodology is well-established, and a precedent for its use in nonmarket research, policy decisions, and Natural Resource Damage Assessment has been set (Boyle 2003; Carson et al. 2001; Rosenberger and Smith 1997).

This study also incorporates measures of relevant attitudes into the estimation of willingness to pay (WTP) using factor and cluster analysis. Attitudes toward forest health, disturbance, and the management thereof vary substantially across society yet are not well understood (Flint et al. 2009; McFarlane et al. 2006). This application demonstrates the interpretive advantages factor and cluster analysis offer to the analysis of valuation data and extends their application into a new context. Factoring captures the covariation in respondent agreement with attitude statements, offering clarity to analysis of the relationship of attitudes, as measured by responses to these statements, with benefits, as measured by responses to the contingent valuation question. Cluster analysis separates respondents into groups with similar 
responses to attitude statements, creating subgroups that likely represent dominant stakeholder positions. Together, these analyses provide nuanced understanding of public benefits, improving the applicability of the survey's results to decisions to be made about managing high-elevation forests.

\section{Background}

Nonmarket benefits of forest invasive species management

Although the nonmarket benefits of forests in general are well documented (Barrio and Loureiro 2010), the nonmarket benefits from managing invasive species in forests are addressed by only a few studies (Holmes et al. 2008; Kramer et al. 2003; Rosenberger and Smith 1997; Rosenberger et al. 2012). These studies take diverse approaches to measuring nonmarket values; some focus on public land and others on private land, some provide estimates by the tree, the acre, or by household per year for an entire program. The disparate approaches makes comparisons difficult. However, this body of literature finds that, in general and on average, people are willing to pay amounts significantly greater than zero to protect forests. For example, Jakus and Smith (1992) use the contingent valuation (CV) method to estimate willingness to pay (WTP) of $\$ 254$ to $\$ 670$ for programs to protect trees against gypsy moth invasions in Pennsylvania and Maryland, and Miller and Lindsay (1993) find an annual WTP of \$43 (median) or $\$ 70$ (average) for gypsy moth control in New Hampshire. Haefele et al. (1992) and Holmes and Kramer (1996) use CV to estimate the benefits from protecting high-elevation spruce-fir forests in the southern Appalachian mountains of the eastern United States against a combination of threats, one of which is exotic insects, with annual estimates of WTP for total forest protection ranging from $\$ 22$ to $\$ 107$. More recently, Moore et al. (2011) use CV to establish support for 
protecting hemlock forests against an invasive insect, the hemlock woolly adelgid, in the Great Smoky Mountains National Park and the Pisgah and Nantahala National Forests, again in the southeastern United States. That study estimates per capita benefits at $\$ 60$ or $\$ 122$, depending on conservation strategy. However, to the best of the authors' knowledge, none have studied the nonmarket benefits of managing an invasive fungus or pathogen in forests; the most similar example is Kovacs et al.'s (2011) use of hedonic modeling to establish the effects of sudden oak death, a non-native forest pathogen, on residential property values on the United States' Pacific Coast, which range from 3-15\% depending on severity and proximity of the disease to the property.

Research on the benefits of managing forests in the Western United States tends to focus on threats other than invasive species. For example, Walsh et al.'s (1990) study finds substantial nonuse values for the protection of ponderosa pines in Colorado from native, mountain pine beetle outbreaks (with only $\$ 14$ of the average annual total value of $\$ 52$ for 150 trees per acre allocated to recreation-use), and Loomis et al. (1996) find significant WTP (\$90 per household per year) to reduce fire hazards to Pacific Northwestern old-growth forests, again with the CV method. Highlighting the importance of the context of management, Chang et al. (2011) find substantially different WTP to control future outbreaks of two different native forest pests, spruce budworms and forest tent caterpillars, in the Canadian provinces of New Brunswick and Saskatchewan, with point estimates of mean WTP ranging between $\$ 33$ and $\$ 104$ per household per year.

Other characteristics of the WPBR threat have not been addressed in the literature to date. For example, most of the studies listed above focus on individual forests, but the fungus causing WPBR is not confined to any particular forest or management unit. As emphasized by Bockstael 
et al. (2000), extrapolating nonmarket benefits from studies on small spatial scales to large geographical areas is an issue with many difficulties. In a recent brief on ecosystem service valuation, Stephen Polasky highlights that such difficulties remain unresolved (Stokstad 2011). The existing literature also tends to target the values of recreational users of the resource, but the management of WPBR would encompass public forests established for ecological conservation as well recreation. Therefore, the benefits that accrue to both users and nonusers of the forests need to be considered. Both the background literature on five-needle pines and focus groups for this project suggest substantial nonmarket benefits associated with the non-recreational aspects of these forests.

\section{Attitudes and Heterogeneity in Nonmarket Valuation}

Attitudes and variations across them have been of interest to economists at least since Krutilla (1967) referred to "the spiritual descendants of John Muir" in demonstration of the existence of nonuse values. Although more specific theories about attitudes can be found, a general definition of the concept from social psychology is that an attitude is "any belief or opinion that has an evaluative component" (Gray 1999 p. 507). In the context of forest management, the public tends to have diverse perspectives on how and why forests should, or should not, be managed. For example, McFarlane et al. (2006) find that attitudes toward managing the mountain pine beetle infestation in Canada vary with whether proposed measures are proactive and with respondents' knowledge and attitudes toward ecological processes. The Moore et al. (2011) study on the management of the hemlock wood adelgid finds a preference for protecting ecological sites up to a minimal level of protection, after which preferences shift toward protecting recreation sites. 
Although attitudes themselves, like economic preferences, are not directly observable, surveys often measure attitudes by asking respondents' to rate their level of agreement (e.g., strongly disagree to strongly agree) with a series of statements. By convention, responses to the statements provide multiple measures of the same underlying attitudes. While this convention helps build robustness with respect to the specific wording of any one statement, the similarity between statements can complicate interpretation of findings and creates high potential for multicollinearity among measures. One approach to addressing both of these issues is factor analysis. Factor analysis is a family of related techniques that allow for linear transformations of the data to reduce the dimensionality of multiple correlated variables.

There is a small but growing use of factor analysis in the broad environmental literature. Examples include Langford et al.'s (2001) open-ended elicitation of WTP for conserving the endangered Mediterranean monk seal, Nunes' (2002) exploration of motivations for WTP for preventing tourism development in Portugal, and others (e.g., Hyytiä and Kola 2006; MartínLópez et al. 2007; Sharp et al. 2011). Other uses of factor analysis explore methodological issues and include examinations of the influence of fringe benefits of survey participation (Hidano et al. 2005), the role of protest responses (Jorgensen et al. 2001; Meyerhoff and Liebe 2006), and the warm-glow effect (Nunes and Schokkaert 2003). Tapsuwan et al. (2010) use factor analysis to determine that all five of their attitude statements convey uniquely meaningful information in their CV study of cave recreation. In our study, factor analysis provides insight into the relationship between attitudes toward forest management and responses to a CV question.

Information about attitudes also can be used to separate respondents into groups with similar perspectives. Market research often uses cluster analysis for this purpose, as in studies focusing on the preferences over genetically modified food (Baker and Burnham 2001; Lusk et 
al. 2001), fresh produce (Bond et al. 2008), and rural tourism in Croatia (Šergo et al. 2010). Though the nonmarket valuation literature has historically focused on using sociodemographics to create groups with homogeneous intra-group characteristics (Aldrich et al. 2007), interest in using attitudes to identify groups with cluster analysis is growing. Some recent studies cluster stakeholders, including forest owners (Kline et al. 2000a; b), ranchers (Bartlett et al. 1989), and users of a wetland area (García-Llorente et al. 2008, 2011) or a national seashore (Sharp et al. 2011), into user types based on responses to attitudes questions. Hyytiä and Kola (2006) use factor scores for a large number of attitudinal variables to cluster respondents to an open-ended $\mathrm{CV}$ question in estimating the benefits of multifunctional agriculture in Finland. Martín-López et al. (2007) cluster respondents to an open-ended CV question based on biodiversity preferences and then use factor analysis to understand variance in WTP for protection of different species. Finally, Aldrich et al. (2007) separate their sample into groups with similar environmental attitudes in estimating WTP to protect the endangered peregrine falcon and shortnose sturgeon, finding convergence between cluster analysis and probabilistic methods for determining subgroups. This study adds to this research by applying cluster analysis to measures of attitudes in the context of forest invasive species management, with an interest in emergent groups within the general public, rather than just within user groups.

\section{Data and Estimation}

Data were collected in a survey administered as part of a broader project on the costs and benefits of managing white pine blister rust in high-elevation forests, described in more detail by Meldrum et al. (2011). After development through a series of four focus groups, a pretest, and extensive consultation with natural scientists, the final survey instrument provided respondents 
with background information, including pictures of the five-needle pine species and WPBR, maps of the species' distributions, and descriptions of distinctive features of healthy highelevation forests. A healthy high-elevation forest was defined as one in which all functional stages of the tree lifecycle occur simultaneously. To establish the plausibility of protecting the high-elevation forests despite the lack of options for abating the spread of WPBR, the questionnaire provided information on treatment options (which could be implemented either proactively or reactively) and typical short-term and long-term effects of these treatments on forests and related services. After the survey described high elevation forests, the threat posed by WPBR, and management options, respondents were asked about their WTP for a program to manage high elevation forests in the Western United Stated for WPBR. The questionnaire concluded with the elicitation of respondents' agreement with numerous statements about highelevation forests, proposed management plans, and related attitudes.

The survey was administered online by Knowledge Networks, Inc., a private research firm, to a probability-based sample of the general population in the Western United States in June of 2010. ${ }^{1}$ This sample was selected by stratified random sampling from a panel of potential respondents who respond to approximately one survey per week in exchange for modest incentives, such as entrance into raffles and special sweepstakes. Knowledge Networks, Inc. recruited its panelists through a combination of random-digit dialing and address-based sampling, thereby accounting for the large number of contemporary households without landline telephones.

\footnotetext{
${ }^{1}$ The sample was drawn only from the population of the Western United States because a national sample with the same number of observations would have resulted in very few observations in some of the Western states (e.g., Wyoming) that were of particular interest for other aspects of the study. More information on the Knowledge Networks panel and methodology can be obtained from Meldrum et al. (2011), contacting the authors, or visiting www.knowledgenetworks.com.
} 
Five hundred forty two of 895 individuals contacted completed the survey over a period of 11 days, for a completion rate of $61 \%$. Twenty of these respondents skipped at least one question analyzed here, leaving a truncated sample of 522 completed surveys ${ }^{2}$. Table 1 provides selected summary statistics on the socioeconomics of the samples and population. Demographics do not statistically differ between the truncated and full samples, and robustness checks demonstrate similar results from estimations for which the full sample can be run, supporting the use of the truncated sample for main results. Probability weights, based on the inverse probability of selection from the population and correcting for oversampling of the Mountain region to ensure adequate coverage, were provided by Knowledge Networks, Inc. and used for all estimations. Wald tests demonstrate that demographics of the weighted, truncated sample do not statistically deviate from those of the population on most measured dimensions, with two exceptions: 1) the racial composition of the weighted sample differs from that of the population; and 2) the weighted sample percentage of households with access to the internet differs from that of the population. ${ }^{3}$ Accordingly, measures of these two demographic factors are included in estimations to accommodate adjusting resulting statistics from the sample to the population's demographics.

\section{Contingent Valuation Question and Analysis}

Survey respondents were asked their willingness to pay (WTP) for a program to treat a large portion of the entire 2 million acres of high-elevation forests in the Western United States for the threat of WPBR. Immediately before answering the contingent valuation $(\mathrm{CV})$ questions,

\footnotetext{
${ }^{2}$ This relatively high completion rate reflects Knowledge Networks, Inc.'s sampling methodology, in which surveys are sent to panels of regular survey participant, as described above.

${ }^{3}$ For respondents without internet access, Knowledge Networks supplies a system that only is capable of accessing their online surveys, thus allowing interactive surveys without changing respondents' access to the internet.
} 
respondents were reminded of their budget constraint and of possible reasons why they might not support the program. Respondents were told the management would be funded through a combination of individual donations, increased visitor fees, and tax increases. The question was then asked in dichotomous-choice CV format. Specifically, respondents were asked:

Suppose managers treat [quantity] of the high-elevation forests in the Western United States. As a result, these acres will be healthy in 100 years from now. The remainder of the acreage would not be treated. Would your household be willing to pay a one-time cost of [bid] to fund this program?

Each respondent was given a randomly selected quantity level of $30 \%, 50 \%$, or $70 \%$ and a randomly selected bid amount of $\$ 10, \$ 25, \$ 50, \$ 100, \$ 250, \$ 500$, or $\$ 1000$. Respondents indicated a "Yes" or "No" response to the CV question. These responses are reported in Table 2, which shows that, in general, fewer respondents faced with high bid values chose "Yes" than those with lower bid values, but there are no clear differences in response patterns among proposed quantities of forests protected. These relationships are explored later in this article.

As typical for single-bounded CV questions, a standard random utility model (McFadden 1974) is assumed for estimating parameters for deriving the WTP, such that:

$$
U_{n i}=V_{n i}+\epsilon_{n i}
$$

where $U_{n i}$ is the unobserved, true utility to individual $n$ if he chooses alternative $i, V_{n i}$ is the observed, systematic component of the utility, and $\epsilon_{n i}$ is a random error. For the dichotomous choice, the respondent is assumed to respond "yes" to option $j$ if and only if $U_{n j}>U_{n 0}$, where $i=0$ corresponds to the status quo case, which is indicated by a "no" response to the CV question. Further assuming errors to be independent and identically distributed draws from the 
type 1 extreme value distribution, as is customary in the random utility model, yields the familiar logit probability model:

$$
P_{n}(y e s)=\frac{e^{V_{n i}}}{1+e^{V_{n i}}}
$$

$V_{n i}$ is assumed to be linear in parameters:

$$
V_{n i}=\alpha+\beta_{1} \text { bid }+\beta_{2} \text { quantity }+\gamma_{1} z_{1}+\cdots+\gamma_{K} z_{K}
$$

where $\alpha$ is the constant associated with the "yes" response and $z_{1}, \ldots, z_{K}$ correspond to $K$ respondent characteristics hypothesized to influence the utility derived from the choice of "yes." Variables representing respondents' race and household access to internet are included to allow extrapolation of results from the sample to the population. Race is represented by dummy variables, with the majority race of White, Non-Hispanic serving as the baseline. Household Internet Access also is represented by a dummy variable, coded as "1" for households with access. Though these variables relate to demographic groups, inference about the choices of those groups based on these coefficients is inappropriate, because no attempt has been made to control for confounding demographic influences, such as income or education. F-adjusted test statistics are reported to provide a comparative measure of model fit, taking survey design into account and thus accommodating the use of probability weights in estimation (Archer and Lemeshow 2006). Higher values correspond to better fit.

Mean WTP is evaluated at the mean level of included covariates and calculated by:

$$
\text { meanWTP }=-\left(\alpha+\beta_{2} \overline{\text { quantıty }}+\gamma_{1} \overline{z_{1}}+\cdots+\gamma_{K} \overline{z_{K}}\right) / \beta_{1}
$$

which adjusts estimated WTP by population-level statistics for race and internet access and also allows for negative WTP (Hanemann 1989), which could be observed if, for example, respondents weigh the non-pecuniary costs of management more heavily than the benefits. Although equation (4) appears to be straightforward regarding how to incorporate attitude 
measures into the WTP equation, practical issues arise with respect to proper specification and resulting interpretation. Therefore, factor analysis and cluster analysis are explored as two approaches to exploiting the information provided by the attitude measures.

\section{Attitudes toward Invasive Species Management in High-Elevation Forests}

Social psychologists have multiple theories on what is considered an "attitude," which are not delved into here. This paper adapts the notion of an attitude articulated by Gray (1999 p. 507) as "any belief or opinion that has an evaluative component." To measure attitudes about the forests and potential management plans, respondents were asked their level of agreement with a series of statements using a Likert scale ranging from 1: "strongly disagree," to 3: "neutral," to 5: "strongly agree." The complete wording of the statements is shown in Table 3 along with a breakdown of responses to each statement. Respondents saw only the statement, not the descriptive label. Reflecting the spectrum of ideas conveyed through a series of focus groups, these statements span a variety of possible motivations for protecting (or not protecting) highelevation forests. Some, such as the Extinction and Future statements, relate both to obligations toward the environment and future generations and to the intrinsic existence value of the forests. Others, such as the Non-intervention and Responsibility statements, relate to the role of humans with respect to nature. The Recreation and Tourism statements focus on the potential use values of the forests, including provision of recreational amenities and supporting tourism-based economies. Finally, the Personal statement reflects the emotional connection that some individuals may feel toward the forests, recognizing that individuals may derive benefit from protecting something personally important to them. 
Despite the statements describing different, specific ideas, their similarity creates the possibility for both the analytical issue of multicollinearity between measures and the practical problem of readily interpretable results. One answer to both these problems is to omit many of the variables from the estimated model, leaving only those most promising for conveying relevant information. However, not only does this approach discard a large amount of information, it also introduces substantial subjectivity through the analyst's decisions over which variables to retain. Factor analysis, which still eliminates information but does so with less assumption required, provides an alternative.

The version of factor analysis used here, iterative principal factoring, focuses on explaining correlations between variables through an iteratively improved estimation. Factor analysis derives weights, called factor loadings, which provide for linear combination of each individual's responses to the attitude statements. A typical further step, called varimax rotation, maximizes the variance of squared factor loadings, creating factors that represent orthogonal dimensions underlying the original data. The result of the linear combination is called a factor score, which can be used in place of the attitude statement responses as an independent variable for further analysis. Each factor score is distributed with mean 0 by construction. In this case, responses to the statements are factored, creating factor scores representing latent attitudes related to multiple observed attitudes responses.

\section{Using Cluster Analysis to Partition Respondents}

The second approach considered for inclusion of attitude measures in the WTP model is cluster analysis. Cluster analysis uses the information gathered with attitude statements to 
partition the sample into distinct subsamples ${ }^{4}$. Like factor analysis, the term cluster analysis refers to a family of techniques (Hamilton 2006). In general, cluster analysis separates observations based on the relationships among observable data. The "K-medians" partitioning cluster method applied here uses the raw responses to attitude statements. As in other partitionclustering techniques, the clusters found by K-medians are defined by a central vector of summary statistics that may not exist as any particular observation in the data (Mooi and Sarstedt 2011). As such, these techniques are better suited for analyzing clusters of unobservable constructs such as attitudes, which can only be measured imperfectly, than are hierarchical techniques that define clusters by similarities in the observed data. In addition, partitioning methods tend to be less affected by outliers and irrelevant clustering variables than other clustering techniques (Mooi and Sarstedt 2011). For $c$ clusters, where $c$ is defined by the analyst through an iterative process of exploring a balance of explanatory and statistical fit, this algorithm starts with a random draw of $c$ observations, which provide initial estimates of the medians of each variable for each cluster (Hamilton 2006). The algorithm then successively draws observations without replacement. It assigns each draw to a cluster based on minimizing the Euclidian distances from the cluster's medians to the draw's data, updating the estimated medians after assigning each draw to a cluster. The generated clusters can be treated as distant subpopulations, allowing estimation of logit models and summary statistics for each cluster individually.

The main empirical difficulty with this technique is its sensitivity to the random draws that provide the initial basis of the clusters. Accordingly, researchers must consider the robustness of estimated clusters to initialization (Juan and Vidal 2000). Here, this sensitivity is

\footnotetext{
${ }^{4}$ Cluster analysis is therefore similar to the techniques of latent class cluster analysis (e.g., Aldrich et al. 2007). Consistent with the findings of Aldrich et al. (2007), the results of ordered logit latent class analysis with these data (not reported in this paper) do not differ substantially from the reported cluster analysis results.
} 
explored by reporting summary statistics of the estimated WTP and descriptive statistics for each cluster over 1000 random initializations, based on the technique proposed by Farber (1994) and recommended by Steinley and Brusco (2007) and Maitra et al. (2010), particularly as the number of replications increases. This straightforward approach provides the nonparametric distribution of estimates over different random initializations.

\section{Results}

Table 3 presents a summary of responses to attitude statements and shows that, on average, respondents agree most strongly with statements relating to existence values (Extinction), moral obligations (Responsibility), and bequest motivations (Future) and less so, though still positively, with statements related to use values (Tourism and Recreation). The only statement toward which respondents typically had a negative attitude states that people should not intervene in high-elevation forests (Non-intervention). This result could relate to a wide variety of attitudes and ideas about the forests and natural resource management, so the disagreement is not unexpected given the support for all other statements.

Table 4 presents correlations between the attitude measures, examining the possibility that the similarity of the Likert-style questions leads to multicollinearity between responses. Correlations between two variables are all low to moderate, following expected patterns, such as stronger correlations existing between Extinction and Future, and between Recreation and Tourism. In addition to pairwise correlations, joint multicollinearity can be tested by using the condition number, of which values greater than 20 suggest potential problems (Belsley 1980). Under this test, the original specification is in danger of multicollinearity, with a condition number of 23.69 . 
The factor analysis suggests a two-factor solution. Table 5 shows the factor loadings for the rotated two-factor solution. A higher factor loading for a given statement signifies that that statement plays a larger role in that factor score. Two factors explain $94 \%$ of the overall variation, and eigenvalues for factors 2 and 3 drop from 0.97 to 0.16 , crossing the common cutoff of 0.5 . The variance in responses that remains unexplained by the full set of factors is called that variable's uniqueness.

Perhaps more importantly than statistical testing for present purposes, the two-factor solution presents an easily interpretable combination of the statements that are demonstrated to be evaluated similarly by respondents on average. The two factors have been labeled "Protect" and "Play" to reflect the statements that dominate the factor loadings for each: Future, Extinction, and Responsibility for the former, and Tourism and Recreation for the latter. That means each individual is assigned a Protect factor, with higher values corresponding to more positive attitudes toward protection-oriented statements, and a Play factor, with higher values corresponding to more positive attitudes toward statements that express the importance of recreational uses of the forests. These scores will be used directly in estimating logit models and in providing a shortcut to understanding the collective attitudes of groups.

The dimensions of the two-factor solution are similar but not completely analogous to the commonly discussed dimensions of use and nonuse values. Factor 1 more closely represents nonuse interests toward the resource, and Factor 2 relates more to use values, but neither of those characterizations are precise. Rather, these two dimensions of Protect and Play closely mirror two major environmental perspectives in North American history. The preservationist ethic, championed by figures such as John Muir, argues for the protection of the environment primarily for its own sake, citing moral, aesthetic, and even spiritual reasons and thus reflecting the Protect 
factor. In contrast, the conservationist mindset, held by the likes of Gifford Pinchot, argues for the environment's protection for more utilitarian reasons (Smith 1998), similar to the Play factor in this context of nontimber forests. Important to the analogy, however, is the recognition that both Muir and Pinchot advocated for use of the natural resources, albeit in very different senses: Muir more for experiential, in-situ uses of the forest, and Pinchot for benefits derived from physical aspects of the forest, such as timber and watershed protection. Like these historic stances, the Factor 1 and Factor 2 both conceivably point to either category of use or nonuse, and thus the labels Protect and Play are applied rather than use and nonuse.

Table 6 presents the main results from various standard conditional logit specifications of the responses to the WTP question. Model I presents the simplest specification, with the righthand side of the equation including only design variables (Bid and Quantity) and demographics. In this model, as in all subsequent models, the coefficient on the bid value is negative and strongly significant. This result is of course expected by economic theory; holding all else equal, fewer respondents are expected to agree to fund the management at higher bid amounts. The coefficient on Quantity, however, is statistically indistinguishable from zero, suggesting that respondents are indifferent to the extent of a management program, at least for treating within the range of 30-70\% of the 2 million acres of high-elevation forests in the Western United States. This result is also consistent across specifications. Although one might expect a positive coefficient on Quantity, this result is consistent both with recent meta-analyses of stated preferences from forest studies (Barrio and Loureiro 2010; Lindhjem 2007) that find WTP tends to be insensitive to the size of a forest, and with Rollins and Lyke (1998), who argue for rapidly diminishing marginal returns for nonuse values. Sample WTP for the average quantity of treated 
forest is strongly different from zero at $\$ 174.34$, with a standard error of $\$ 41.39$. Adjusting for population demographics shifts the point estimate to $\$ 149.76$, standard error of $\$ 35.36$.

Model II introduces the use of measures of attitudes but only includes two of the measures, because the full set of measures cannot be estimated together due to multicollinearity issues. The included measures, Extinction and Recreation, are selected for their representativeness of the two underlying attitudes types that are suggested by the factor analysis. Despite intuitively pertaining to different ideas, however, these two measures are non-negligibly correlated with each other, as shown in Table 4, and thus this model should be considered exploratory rather than definitive. In this model, the coefficient on Extinction is positive and strongly significant, whereas that on Recreation is not statistically different from zero.

Model III provides the best fit of the tested models. Additionally, in an important distinction from Model II, the interpretation of the factor coefficients in Model III is not confounded by potential collinearity because the two factors are uncorrelated with each other by construction. In this model, the coefficient on Bid and the estimated average WTP remains consistent with other models, demonstrating the robustness of the original result from estimating without attitudes. However, Model III outperforms the others by presenting the information conveyed by the common variation in the seven attitudes measures concisely, in two variables, and by demonstrating the effect of these two variables on the probability that respondents support the management program. The coefficient on Factor 1, labeled Protect, is positive, strongly significant, and more than four times larger than the coefficient on Factor 2, labeled Play, with the latter not significantly different from zero. Because of the independence of the factor variables, this model demonstrates that attitudes toward protection strongly outweigh those toward recreational use in influencing support for managing WPBR in high-elevation forests. 
Further insight into the role of attitudes comes from the results of cluster analysis. Because of its interpretative value, results of a three cluster model are presented. This model is selected although relative Caliński/Harabasz pseudo-F statistics (Caliński and Harabasz 1974), of which higher values demonstrate greater separation between clusters and thus more natural groupings, demonstrate a statistic preference for the two cluster model. Presentation of the three cluster model is warranted by its representation of a fair amount more nuance in what can be expected to be substantial stakeholder positions regarding a policy for managing WPBR than that shown in the two cluster model.

Figure 1 plots the distribution of the estimated WTP for each of the three clusters created over 1000 random initialization trials, and Table 7 shows summary statistics from these Monte Carlo procedures. Though highly variable, Cluster 1 consistently exhibits a low WTP, and average WTP estimates for Clusters 2 and 3 consistently exceed the combined sample's estimate. The figure also depicts a smoothed, nonparametric distribution of the weighted average of the three clusters' estimates for each of the randomizations. The mean value of this distribution of weighted average WTP is $\$ 203.99$, which is quite close to the sample estimates of WTP reported for the non-partitioned models. Table 7 reports the distributions of each cluster's point estimates, their standard errors, and mean factor scores across the 1000 trials. Factor scores are not used in estimation but rather are used as a short-hand for describing results. Over the 1000 trials, the clusters split the sample roughly in even thirds, with between 157 and 194 respondents being assigned to each cluster on average. The Indifferent cluster appears to adhere to its label on average, with imprecise WTP estimates averaging to $-\$ 86$ and low mean factor scores. The Protect and Play cluster consistently corresponds to a high mean WTP for management, averaging about $\$ 323$ per household, and factor scores for both Protect and Play are consistently 
high. The Protect cluster averages a mean WTP nearly as high as the Protect and Play cluster, despite a much lower mean factor score for Play and somewhat lower for Protect.

For further insight into the nature of the different clusters, Table 8 presents parameters and statistics pertaining to a particular random initialization of the cluster analysis, which is selected because of its representativeness of the qualitative pattern of typical results from the Monte Carlo analysis with respect to factor scores and CV question coefficients. For this representative result, as in Table 7, mean factor scores are presented for each cluster to aid interpretation, but these data are not used in estimating either the clusters or the choice parameters.

As shown, Cluster 1 consists of $30 \%$ of the sample and is named the "indifferent" cluster, because it has a point estimate of WTP that is not statistically different from zero. As expected, this group's aggregated attitudes lean strongly away from supporting management, with a significant level of disagreement with protection attitude statements compared to the full sample's average level of agreement. In contrast, the mean WTP estimates, \$310.44 and \$309.08, based on Clusters 2 and 3, respectively, are both statistically different from zero. While Cluster 3 includes respondents with higher than average levels of agreement with both Protect and Play attitudes, Cluster 2 statistically differs from the sample's average positively for the Protect factor and negatively for the Play factor, demonstrating the group's higher-than-average agreement with Protection statements and lower-than-average agreement with Play statements. In other words, while members of both clusters with a positive and significant WTP care more than average about protecting the health of the forests, members of Cluster 3 (32\% of the respondents) also care substantially more about recreation and tourism compared to the respondents in Cluster 2 (38\% of the respondents). 


\section{Conclusion}

The primary conclusion of this study is that, on average, individuals in the Western United States are willing to pay $\$ 153.56$ for a program to manage white pine blister rust across the range of high-elevation white pine forests in the Western United States, with a 95\% confidence interval $^{5}$ placing that value between $\$ 87.91$ and $\$ 219.22$. This estimate comes from Model III on Table 6, which provides the best fit of the data by using the factor score representations of agreement with attitudes statements. Considering that this pertains to a onetime payment per household, this estimate is in line with estimates of WTP for forest protection programs in similar research, such as Kramer et al.'s (2003) reviewed range of roughly $\$ 20$ to $\$ 100$ per household per year, Moore et al.'s (2011) estimate of \$122 per capita for the optimal strategy of protecting specific national parks and forests from the hemlock woolly adelgid, and Chang et al.'s (2011) estimated WTP for controlling spruce budworms and forest tent caterpillars of between $\$ 33$ and $\$ 104$ per household per year. At the same time, when scaled by the roughly 27 million households in the sampled population, an average of $\$ 153.56$ corresponds to an aggregate willingness to pay of $\$ 4.1$ billion. Even at the low end of the $95 \%$ confidence interval, an average WTP of $\$ 87.91$ per household translates to $\$ 2.4$ billion. Thus, these estimates of the benefits of such management make a compelling case for devoting significant resources to addressing the threat posed by WPBR to high elevation forests in the Western United States.

Additional insights from these data accrue from the application of factor and cluster analyses. The two observed factors map the Likert-scale questions into two dimensions, reflecting attitudes toward the long-run existence of the forests on the one hand, and toward

\footnotetext{
${ }^{5}$ The confidence interval is generated by assuming a normally distributed post-estimation standard error, which is calculated via delta method (Oehlert 1992).
} 
recreational use values on the other. Including the factors in regression analysis demonstrates that, overall, WTP for WPBR management relates more to interest in the long-run existence of high-elevation pine forests than to interest in the forests' role in recreation and tourism. Such information should encourage decision-makers acting on the public's behalf to prioritize the long-term health of the forests over the short-term recreational interests in the likely case that deciding over management options requires a tradeoff between the two.

At the same time, cluster analysis suggests heterogeneity in the motivations for valuing the management. Although existence values are much more strongly associated with willingness to pay than use values on average, the approximately one-third of the sample that feels that recreational uses of the forest are important is willing to pay approximately the same amount as the one-third who emphasize the importance only of the existence values. Accordingly, management that curtails recreational activities could substantially undercut the level of support from a large portion of the population currently in favor of management. In contrast, those disagreeing with the most with statements about the importance of high-elevation forests and managing for WPBR are collectively not willing to pay for such management. Though not surprising, this result should improve confidence in the results by demonstrating the extent to which not all respondents agree with the majority, or aggregated, preferences. In addition, this finding demonstrates the existence of a concentrated group of individuals who do not significantly value the potential management and, accordingly, may oppose the spending of public funds for it. From a policy perspective, this report is important for suggesting that the implementation of treatment might still be politically contentious, despite the estimated mean willingness to pay demonstrating a strong average level of support for treatment. 
Overall, the take-home message of this analysis mirrors the sentiment conveyed in focus groups during survey development: though not a source of market products such as timber, highelevation pine forests are valuable. Specific sentiments vary, but people generally agree on the importance of protecting the five-needle pine species from extinction and helping these forests exist for future generations. Accordingly, the general public of the Western United States is willing to pay substantial sums for management programs that promise to improve the chances of long-run forest health in the face of the threat of white pine blister rust. This aggregate result is robust to the different analyses of heterogeneity explored; the bottom line WTP is consistent regardless of estimation method. At the same time, the further analyses explored in this paper demonstrate the importance of considering of the heterogeneity of benefits of such a policy. 


\section{References}

Aldrich, G. A., Grimsrud, K. M., Thacher, J. A., and Kotchen, M. J. (2007). "Relating environmental attitudes and contingent values: how robust are methods for identifying preference heterogeneity?" Environmental and Resource Economics, 37(4), 757-775.

Baker, G. A., and Burnham, T. A. (2001). "Consumer Response to Genetically Modified Foods: Market Segment Analysis and Implications for Producers and Policy Makers.” Journal of Agricultural and Resource Economics, 26(2), 387-403.

Barrio, M., and Loureiro, M. L. (2010). "A meta-analysis of contingent valuation forest studies." Ecological Economics, 69(5), 1023-1030.

Bartlett, E. T., Taylor, R. G., McKean, J. R., and Hof, J. G. (1989). "Motivation of Colorado Ranchers with Federal Grazing Allotments." Journal of Range Management, 42(6), 454-457.

Belsley, D. A. (1980). "On the efficient computation of the nonlinear full-information maximumlikelihood estimator." Journal of Econometrics, 14(2), 203-225.

Bestard, A. B., and Font, A. R. (2010). "Estimating the aggregate value of forest recreation in a regional context." Journal of Forest Economics, 16(3), 205-216.

Bockstael, N. E., Freeman, A. M., Kopp, R. J., Portney, P. R., and Smith, V. Kerry. (2000). “On Measuring Economic Values for Nature †." Environ. Sci. Technol., 34(8), 1384-1389.

Bond, C. A., Champ, P. A., Meldrum, J. R., and Schoettle, A. W. (2011). "Investigating the Optimality of Proactive Management of an Invasive Forest Pest." The future of high-elevation, five-needle white pines in Western North America: Proceedings of the High Five Symposium, U.S. Department of Agriculture, Forest Service, Rocky Mountain Research Station, Missoula, MT, 295-302.

Bond, C. A., Thilmany, D., and Keeling Bond, J. (2008). "Understanding consumer interest in product and process-based attributes for fresh produce." Agribusiness, 24(2), 231-252.

Boyle, K. J. (2003). "Contingent Valuation in Practice." A Primer on Nonmarket Valuation, P. A. Champ, K. J. Boyle, and T. C. Brown, eds., Kluwer Academic Publishers, Boston, 111-170.

Burns, K. S., Schoettle, A. W., Jacobi, W. R., and Mahalovich, M. F. (2008). Options for the Management of White Pine Blister Rust in the Rocky Mountain Region. General Technical Report, U.S. Department of Agriculture, Forest Service, Rocky Mountain Research Station, Fort Collins, CO, 26.

Caliński, T., and Harabasz, J. (1974). "A dendrite method for cluster analysis." Communications in Statistics, 3(1), 1-27.

Carson, R. T., Flores, N. E., and Meade, N. F. (2001). "Contingent Valuation: Controversies and Evidence." Environmental and Resource Economics, 19(2), 173.

Chang, W., Lantz, V. A., and MacLean, D. A. (2011). "Social Benefits of Controlling Forest Insect Outbreaks: A Contingent Valuation Analysis in Two Canadian Provinces." Canadian Journal of Agricultural Economics/Revue canadienne d'agroeconomie, 59(3), 383-404.

Faber, V. (1994). "Clustering and the Continuous k-Means Algorithm.” Los Alamos Science, 22, 138144.

Flint, C. G., McFarlane, B., and Müller, M. (2009). "Human dimensions of forest disturbance by insects: An international synthesis." Environmental Management, 43(6), 1174-1186.

García-Llorente, M., Martín-López, B., González, J. A., Alcorlo, P., and Montes, C. (2008). “Social perceptions of the impacts and benefits of invasive alien species: Implications for management." Biological Conservation, 141(12), 2969-2983.

García-Llorente, M., Martín-López, B., Nunes, P. A. L. D., González, J. A., Alcorlo, P., and Montes, C. (2011). "Analyzing the Social Factors That Influence Willingness to Pay for Invasive Alien Species Management Under Two Different Strategies: Eradication and Prevention." Environmental Management, 48, 418-435.

Gray, P. (1999). "Social Perception and Attitude." Psychology, Worth Publishers, 507-521.

Haefele, M., Kramer, R. A., and Holmes, T. P. (1992). Estimating the total value of forest quality in highelevation spruce-fir forests. Proceedings of the Conference: The Economic Value of Wilderness, 
General Technical Report, U.S. Department of Agriculture, Forest Service, Southeastern Forest Experiment Station, Asheville, NC, 91-96.

Hamilton, L. C. (2006). Statistics with Stata: Updated for Version 9. Thompson Brooks/Cole, Belmont, CO.

Hanemann, W. M. (1989). "Welfare Evaluations in Contingent Valuation Experiments with Discrete Response Data: Reply.” American Journal of Agricultural Economics, 71(4), 1057-1061.

Hidano, N., Kato, T., and Aritomi, M. (2005). "Benefits of participating in contingent valuation mail surveys and their effects on respondent behavior: a panel analysis." Ecological Economics, 52(1), 63-80.

Holmes, T. P., Aukema, J. E., Von Holle, B., Liebhold, A., and Sills, E. (2009). "Economic Impacts of Invasive Species in Forests." Annals of the New York Academy of Sciences, 1162(1), 18-38.

Holmes, T. P., Bell, K. P., Byrne, B., and Wilson, J. S. (2008). "Economic Aspects of Invasive Forest Pest Management." The Economics of Forest Disturbances, T. P. Holmes, J. P. Prestemon, and Karen L. Abt, eds., Springer Netherlands, Dordrecht, 381-406.

Holmes, T. P., and Kramer, R. A. (1996). "Contingent valuation of ecosystem health." Ecosystem Health, 2, 56-60.

Hynes, S., Campbell, D., and Howley, P. (2011). “A Holistic vs. an Attribute-based Approach to Agri-Environmental Policy Valuation: Do Welfare Estimates Differ?” Journal of Agricultural Economics, 62(2), 305-329.

Hyytiä, N., and Kola, J. (2006). "Finnish citizens' attitudes towards multifunctional agriculture." International Food and Agribusiness Management Review, 9(3), 1-22.

Jakus, P., and Smith, Vincent Kerry. (1992). Measuring use and nonuse values for landscape amenities: a contingent behavior analysis of gypsy moth control. Quality of the Environment Division, Resources for the Future.

Jorgensen, B. S., Wilson, M. A., and Heberlein, T. A. (2001). "Fairness in the contingent valuation of environmental public goods: attitude toward paying for environmental improvements at two levels of scope.” Ecological Economics, 36(1), 133-148.

Juan, A., and Vidal, E. (2000). "Comparison of Four Initialization Techniques for the K-Medians Clustering Algorithm.” Advances in Pattern Recognition, F. J. Ferri, J. M. Iñesta, A. Amin, and P. Pudil, eds., Springer Berlin Heidelberg, Berlin, Heidelberg, 842-852.

Kinloch, B. B. (2003). "White Pine Blister Rust in North America: Past and Prognosis." Phytopathology, 93, 1044-1047.

Kline, J. D., Alig, R. J., and Johnson, R. L. (2000a). "Fostering the production of nontimber services among forest owners with heterogeneous objectives." Forest Science, 46(2), 302-311.

Kline, J. D., Alig, R. J., and Johnson, R. L. (2000b). "Forest owner incentives to protect riparian habitat." Ecological Economics, 33(1), 29-43.

Kovacs, K., Holmes, T., Englin, J., and Alexander, J. (2011). "The Dynamic Response of Housing Values to a Forest Invasive Disease: Evidence from a Sudden Oak Death Infestation." Environmental and Resource Economics, 49(3), 445-471.

Kramer, R. A., Holmes, T. P., and Haefele, M. (2003). "Contingent valuation of forest ecosystem protection.” Forests in a Market Economy, E. O. Sills and Karen Lee Abt, eds., Kluwer Academic Publishers, Boston, 303-320.

Krutilla, J. V. (1967). “Conservation reconsidered.” American Economic Review, 57(4), 777-786.

Langford, I. H., Skourtos, M. S., Kontogianni, A., Day, R. J., Georgiou, S., and Bateman, I. J. (2001). "Use and nonuse values for conserving endangered species: the case of the Mediterranean monk seal." Environment and Planning A, 33(12), 2219 - 2233.

Liebhold, A. M., MacDonald, W. L., Bergdahl, D., and Mastro, V. C. (1995). Invasion by Exotic Forest Pests: A Threat to Forest Ecosystems. Forest Science Monographs, Supplement to Forest Science, Volume 41 Number 2, Society of American Foresters.

Lindhjem, H. (2007). "20 years of stated preference valuation of non-timber benefits from Fennoscandian forests: A meta-analysis." Journal of Forest Economics, 12(4), 251-277. 
Logan, J. A., and Powell, J. A. (2001). "Ghost Forests, Global Warming, and the Mountain Pine Beetle (Coleoptera $\square$ : Scolytidae)." American Entomologist, 47(3), 160-173.

Loomis, J. B., González-Cabán, A., and Gregory, R. (1996). A contingent valuation study of the value of reducing fire hazards to old-growth forests in the Pacific Northwest. Research Paper, U.S. Department of Agriculture, Forest Service, Pacific Southwest Research Station, Albany, CA, 24.

Lusk, J. L., Daniel, M. S., Mark, D. R., and Lusk, C. L. (2001). "Alternative Calibration and Auction Institutions for Predicting Consumer Willingness to Pay for Nongenetically Modified Corn Chips." Journal of Agricultural and Resource Economics, 26(1), 40-57.

Maitra, R., Peterson, A. D., and Ghosh, A. P. (2010). "A systematic evaluation of different methods for initializing the K-means clustering algorithm." IEEE Transactions on Knowledge and Data Engineering.

Maloy, O. C. (1997). "White pine blister rust control in North America: A Case History." Annual Review of Phytopathology, 35, 87-109.

Martín-López, B., Montes, C., and Benayas, J. (2007). "The non-economic motives behind the willingness to pay for biodiversity conservation.” Biological Conservation, 139(1-2), 67-82.

Mattson, D. J., Blanchard, B. M., and Knight, R. R. (1992). "Yellowstone Grizzly Bear Mortality, Human Habituation, and Whitebark Pine Seed Crops." The Journal of Wildlife Management, 56(3), 432442.

McFadden, D. (1974). "Conditional logit analysis of qualitative choice behavior." Frontiers in Econometrics, Academic Press, New York, NY, 105-142.

McFarlane, B. L., Stumpf-Allen, R. C. G., and Watson, D. O. (2006). "Public perceptions of natural disturbance in Canada's national parks: The case of the mountain pine beetle (Dendroctonus ponderosae Hopkins)." Biological Conservation, 130(3), 340-348.

Meldrum, J. R., Champ, P. A., and Bond, C. A. (2011). "Valuing the Forest for the Trees: Willingness to Pay for White Pine Blister Rust Management." The future of high-elevation, five-needle white pines in Western North America: Proceedings of the High Five Symposium, R. E. Keane, D. F. Tomback, M. P. Murray, and C. M. Smith, eds., U.S. Department of Agriculture, Forest Service, Rocky Mountain Research Station, Missoula, MT, 226-234.

Meyerhoff, J., and Liebe, U. (2006). "Protest beliefs in contingent valuation: Explaining their motivation." Ecological Economics, 57(4), 583-594.

Miller, J. D., and Lindsay, B. E. (1993). "Willingness to pay for a state gypsy moth control program in New Hampshire: a contingent valuation case study." Journal of Economic Entomology, 86, 828837.

Mooi, E., and Sarstedt, M. (2011). "Cluster Analysis." A Concise Guide to Market Research: The Process, Data, and Methods Using IBM SPSS Statistics, Springer, 237-284.

Moore, C. C., Holmes, T. P., and Bell, K. P. (2011). "An attribute-based approach to contingent valuation of forest protection programs." Journal of Forest Economics, 17(1), 35-52.

Nunes, P. A. L. D. (2002). "Using factor analysis to identify consumer preferences for the protection of a natural area in Portugal." European Journal of Operational Research, 140(2), 499-516.

Nunes, P. A. L. D., and Schokkaert, E. (2003). "Identifying the warm glow effect in contingent valuation." Journal of Environmental Economics and Management, 45(2), 231-245.

Oehlert, G. W. (1992). "A Note on the Delta Method." The American Statistician, 46(1), 27-29.

Petit, C. (2007). "In the Rockies, Pines Die and Bears Feel It." The New York Times.

Pimentel, D., Zuniga, R., and Morrison, D. (2005). "Update on the environmental and economic costs associated with alien-invasive species in the United States." Ecological Economics, 52(3), 273288.

Robbins, J. (2010). “Old Trees May Soon Meet Their Match.” The New York Times.

Rollins, K., and Lyke, A. (1998). "The Case for Diminishing Marginal Existence Values." Journal of Environmental Economics and Management, 36(3), 324-344. 
Rosenberger, R. S., Bell, L. A., Champ, P. A., and Smith, E. L. (2012). Nonmarket Economic Values of Forest Insect Pests: An Updated Literature Review. General Technical Report, U.S. Department of Agriculture, Forest Service, Rocky Mountain Research Station, Fort Collins, CO, 46.

Rosenberger, R. S., and Smith, E. L. (1997). Nonmarket economic impacts of forest insect pests: a literature review. General Technical Report, U.S. Department of Agriculture, Forest Service, Pacific Southwest Research Station, Albany, CA, 38.

Samman, S., Schwandt, J. W., and Wilson, J. L. (2003). Managing for Healthy White Pine Ecosystems in the United States to Reduce the Impacts of White Pine Blister Rust. U.S. Department of Agriculture, Forest Service, Northern Region, Missoula, MT.

Schoettle, A. W., and Sniezko, R. A. (2007). "Proactive intervention to sustain high elevation pine ecosystems threatened by white pine blister rust." Journal of Forest Reseach, 12, 327-336.

Schwandt, J. W. (2006). Whitebark Pine in Peril: A Case for Restoration. U.S. Department of Agriculture, Forest Service, Forest Health Protection, Coeur d'Alene, ID.

Šrergo, Z., Težak, A., and Poropat, A. (2010). "Tourists' attitudes and opinions on the features of coastal agritourisms: The case of Istria County, Croatia." New Medit: Mediterranean Journal of Economics, Agriculture and Environment, 9(2), 56-64.

Sharp, R. L., Larson, L. R., and Green, G. T. (2011). "Factors influencing public preferences for invasive alien species management." Biological Conservation, 144(8), 2097-2104.

Sills, E. O., and Abt, Karen Lee. (2003). Forests in a Market Economy. Springer.

Steinley, D., and Brusco, M. J. (2007). "Initializing K-means Batch Clustering: A Critical Evaluation of Several Techniques." Journal of Classification, 24, 99-121.

Stokstad, E. (2011). “Appraising U.K. Ecosystems, Report Envisions Greener Horizon.” Science, 332(6034), 1139.

Tapsuwan, S., Burton, M., and Perriam, J. (2010). "A multivariate probit analysis of willingness to pay for cave conservation: a case study of Yanchep National Park, Western Australia." Tourism Economics, 16(4), 1019-1035.

Tomback, D. F., and Kendall, K. C. (2001). "Biodiversity losses: the downward spiral." Whitebark Pine Communities, D. F. Tomback, S. F. Arno, and R. E. Keane, eds., Island Press, Washington, DC, 243-262.

U.S. Fish and Wildlife Service. (2011). "News Release: Whitebark Pine to be Designated a Candidate for Endangered Species Protection."

Walsh, R. G., Bjonback, R. D., Aiken, R. A., and Rosenthal, D. H. (1990). "Estimating the public benefits of protecting forest quality." Journal of Environmental Management, 30(2), 175-189. 


\section{List of tables and figures:}

Table 1. Demographics of samples and study population

Table 2. Proportion of yes responses to contingent valuation choice for each pair of randomly selected Bid and Quantity values

Table 3. Attitudes responses (percentage of respondents, $n=522$ )

Table 4. Correlation matrix for attitudes measures

Table 5. Factor loadings for attitudes

Table 6. Standard logit models with attitudes measures; dependent variable is response to WTP question: $1=$ yes; $0=$ no. $(\mathrm{N}=522)$

Table 7. Cluster analysis results, averaged over 1000 random initializations; dependent variable is response to WTP question: $1=$ yes; $0=$ no

Table 8. Cluster analysis and standard logit model for a "typical" set of three clusters; dependent variable is response to WTP question: $1=$ yes; $0=$ no.

Figure 1. Frequency of estimated willingness to pay (WTP) for the three clusters and their average, for each of 1000 trials 


\begin{tabular}{|c|c|c|c|c|}
\hline Sample & Raw & $\begin{array}{l}\text { Truncated, } \\
\text { Weighed }\end{array}$ & Population $^{\mathrm{a}}$ & $\begin{array}{l}\text { Test of } \\
\text { equality }\end{array}$ \\
\hline Census division & & & & 0.43 \\
\hline Pacific (WA, OR, CA) & $29 \%$ & $68 \%$ & $66 \%$ & \\
\hline $\begin{array}{l}\text { Mountain (MT, ID, WY, CO, } \\
\text { NM, AZ, UT, NV) }\end{array}$ & $71 \%$ & $32 \%$ & $34 \%$ & \\
\hline Gender & & & & 0.79 \\
\hline Male & $47 \%$ & $49 \%$ & $50 \%$ & \\
\hline Female & $53 \%$ & $51 \%$ & $50 \%$ & \\
\hline Age & & & & 0.92 \\
\hline $18-29$ & $16 \%$ & $22 \%$ & $24 \%$ & \\
\hline $30-44$ & $22 \%$ & $29 \%$ & $28 \%$ & \\
\hline $45-59$ & $30 \%$ & $26 \%$ & $27 \%$ & \\
\hline $60+$ & $31 \%$ & $23 \%$ & $22 \%$ & \\
\hline Educational Attainment & & & & 0.67 \\
\hline Less than High School & $10 \%$ & $14 \%$ & $16 \%$ & \\
\hline High School & $23 \%$ & $25 \%$ & $27 \%$ & \\
\hline Some College & $35 \%$ & $32 \%$ & $31 \%$ & \\
\hline Bachelor and beyond & $32 \%$ & $30 \%$ & $26 \%$ & \\
\hline Race / Ethnicity & & & & 0.01 \\
\hline White, Non-Hispanic & $75 \%$ & $60 \%$ & $55 \%$ & \\
\hline Black, Non-Hispanic & $2 \%$ & $2 \%$ & $5 \%$ & \\
\hline Other, Non-Hispanic & $6 \%$ & $10 \%$ & $10 \%$ & \\
\hline Hispanic & $14 \%$ & $24 \%$ & $29 \%$ & \\
\hline 2+ Races, Non-Hispanic & $2 \%$ & $3 \%$ & $2 \%$ & \\
\hline \multicolumn{5}{|l|}{ Other Criteria } \\
\hline In a Metropolitan Statistical Area & $86 \%$ & $91 \%$ & $91 \%$ & 0.96 \\
\hline Household Internet Access & $76 \%$ & $67 \%$ & $76 \%$ & 0.02 \\
\hline$N$ & 542 & 522 & $27,115,377$ & \\
\hline
\end{tabular}

Notes: ${ }^{a}$ Source - U.S. Census Bureau: 2007 Current Population Survey, 2009 Population Estimates Program, and 2006-2008 American Community Survey 3-Year Estimates. ${ }^{b}$ p-values from Adjusted Wald tests for equivalence of "Truncated, Weighted" sample means to Population means for each category; Reject equivalence if $\mathrm{p}<0.10$ 


\begin{tabular}{|c|c|c|c|c|c|c|c|c|}
\hline Bid & $\$ 10$ & $\$ 25$ & $\$ 50$ & $\$ 100$ & $\$ 250$ & $\$ 500$ & $\$ 1000$ & All bids \\
\hline \multirow{2}{*}{ Quantity $=30 \%$} & $19 / 23$ & $18 / 23$ & $12 / 27$ & $18 / 31$ & $6 / 20$ & $9 / 33$ & $1 / 20$ & $83 / 177$ \\
\hline & $83 \%$ & $78 \%$ & $44 \%$ & $58 \%$ & $30 \%$ & $27 \%$ & $5 \%$ & $47 \%$ \\
\hline \multirow{2}{*}{ Quantity $=50 \%$} & $27 / 29$ & $14 / 20$ & $19 / 30$ & $10 / 26$ & $6 / 22$ & $12 / 31$ & $3 / 18$ & $91 / 176$ \\
\hline & $93 \%$ & $70 \%$ & $63 \%$ & $38 \%$ & $27 \%$ & $39 \%$ & $17 \%$ & $52 \%$ \\
\hline \multirow{2}{*}{ Quantity $=70 \%$} & $17 / 19$ & $18 / 30$ & $9 / 18$ & $16 / 28$ & $11 / 26$ & $7 / 31$ & $1 / 17$ & $79 / 169$ \\
\hline & $89 \%$ & $60 \%$ & $50 \%$ & $57 \%$ & $42 \%$ & $23 \%$ & $6 \%$ & $47 \%$ \\
\hline \multirow{2}{*}{ All quantities } & $63 / 71$ & $50 / 73$ & $40 / 75$ & $44 / 85$ & $23 / 68$ & $28 / 95$ & $5 / 55$ & $253 / 522$ \\
\hline & $89 \%$ & $68 \%$ & $53 \%$ & $52 \%$ & $34 \%$ & $29 \%$ & $9 \%$ & $48 \%$ \\
\hline
\end{tabular}




\begin{tabular}{|c|c|c|c|c|c|c|}
\hline Label & Statement & $\begin{array}{l}\text { Strongly } \\
\text { Disagree }\end{array}$ & Disagree & Neutral & Agree & $\begin{array}{c}\text { Strongly } \\
\text { Agree }\end{array}$ \\
\hline Extinction & $\begin{array}{l}\text { Protecting five-needled } \\
\text { pines from the threat of } \\
\text { extinction is important. }\end{array}$ & $2 \%$ & $3 \%$ & $20 \%$ & $30 \%$ & $45 \%$ \\
\hline Recreation & $\begin{array}{l}\text { It is important that } \\
\text { high-elevation forests } \\
\text { provide recreation } \\
\text { activities, such as } \\
\text { hiking or camping. }\end{array}$ & $3 \%$ & $11 \%$ & $34 \%$ & $29 \%$ & $22 \%$ \\
\hline Future & $\begin{array}{l}\text { It is important that } \\
\text { high-elevation forests } \\
\text { exist for future } \\
\text { generations. }\end{array}$ & $2 \%$ & $2 \%$ & $16 \%$ & $30 \%$ & $52 \%$ \\
\hline Personal & $\begin{array}{l}\text { It is important that } \\
\text { forests I am personally } \\
\text { attached to are treated } \\
\text { for WPBR. }\end{array}$ & $6 \%$ & $6 \%$ & $41 \%$ & $28 \%$ & $20 \%$ \\
\hline Tourism & $\begin{array}{l}\text { Tourism related to high- } \\
\text { elevation forests is } \\
\text { important. }\end{array}$ & $6 \%$ & $15 \%$ & $48 \%$ & $20 \%$ & $11 \%$ \\
\hline $\begin{array}{l}\text { Non- } \\
\text { intervention }\end{array}$ & $\begin{array}{l}\text { People should not } \\
\text { intervene in high- } \\
\text { elevation forests. }\end{array}$ & $23 \%$ & $32 \%$ & $29 \%$ & $11 \%$ & $5 \%$ \\
\hline $\begin{array}{l}\text { Respons- } \\
\text { ibility }\end{array}$ & $\begin{array}{l}\text { Humans have the } \\
\text { responsibility to protect } \\
\text { ecosystems from pests } \\
\text { or diseases that humans } \\
\text { introduced. }\end{array}$ & $2 \%$ & $3 \%$ & $24 \%$ & $34 \%$ & $37 \%$ \\
\hline
\end{tabular}




\begin{tabular}{lccccccc}
\hline Table 4. Correlation matrix for attitudes measures & & & & \\
\hline & $\begin{array}{c}\text { Extinc- } \\
\text { tion }\end{array}$ & $\begin{array}{c}\text { Recrea- } \\
\text { tion }\end{array}$ & Future & Personal & Tourism & $\begin{array}{c}\text { Non-int- } \\
\text { ervention }\end{array}$ & $\begin{array}{c}\text { Respon- } \\
\text { sibility }\end{array}$ \\
\hline Extinction & 1.00 & & & & & & \\
Recreation & 0.37 & 1.00 & & & & & \\
Future & 0.74 & 0.46 & 1.00 & & & & \\
Personal & 0.51 & 0.39 & 0.48 & 1.00 & & & \\
Tourism & 0.27 & 0.61 & 0.28 & 0.30 & 1.00 & & \\
Non-intervention & -0.36 & -0.07 & -0.34 & -0.28 & 0.03 & 1.00 & \\
Responsibility & 0.55 & 0.19 & 0.50 & 0.40 & 0.10 & -0.35 & 1.00 \\
\hline
\end{tabular}




\begin{tabular}{lccc}
\hline \multicolumn{4}{l}{ Table 5. Factor loadings for attitudes } \\
\hline & $\begin{array}{c}\text { Factor 1 } \\
\text { "Protect" }\end{array}$ & $\begin{array}{c}\text { Factor 2 } \\
\text { "Play" }\end{array}$ & Uniqueness \\
\hline Extinction & 0.82 & 0.23 & 0.27 \\
Recreation & 0.26 & 0.79 & 0.31 \\
Future & 0.77 & 0.30 & 0.32 \\
Personal & 0.55 & 0.31 & 0.60 \\
Tourism & 0.10 & 0.75 & 0.43 \\
Non-intervention & -0.50 & 0.09 & 0.74 \\
Responsibility & 0.67 & 0.02 & 0.55 \\
\hline
\end{tabular}




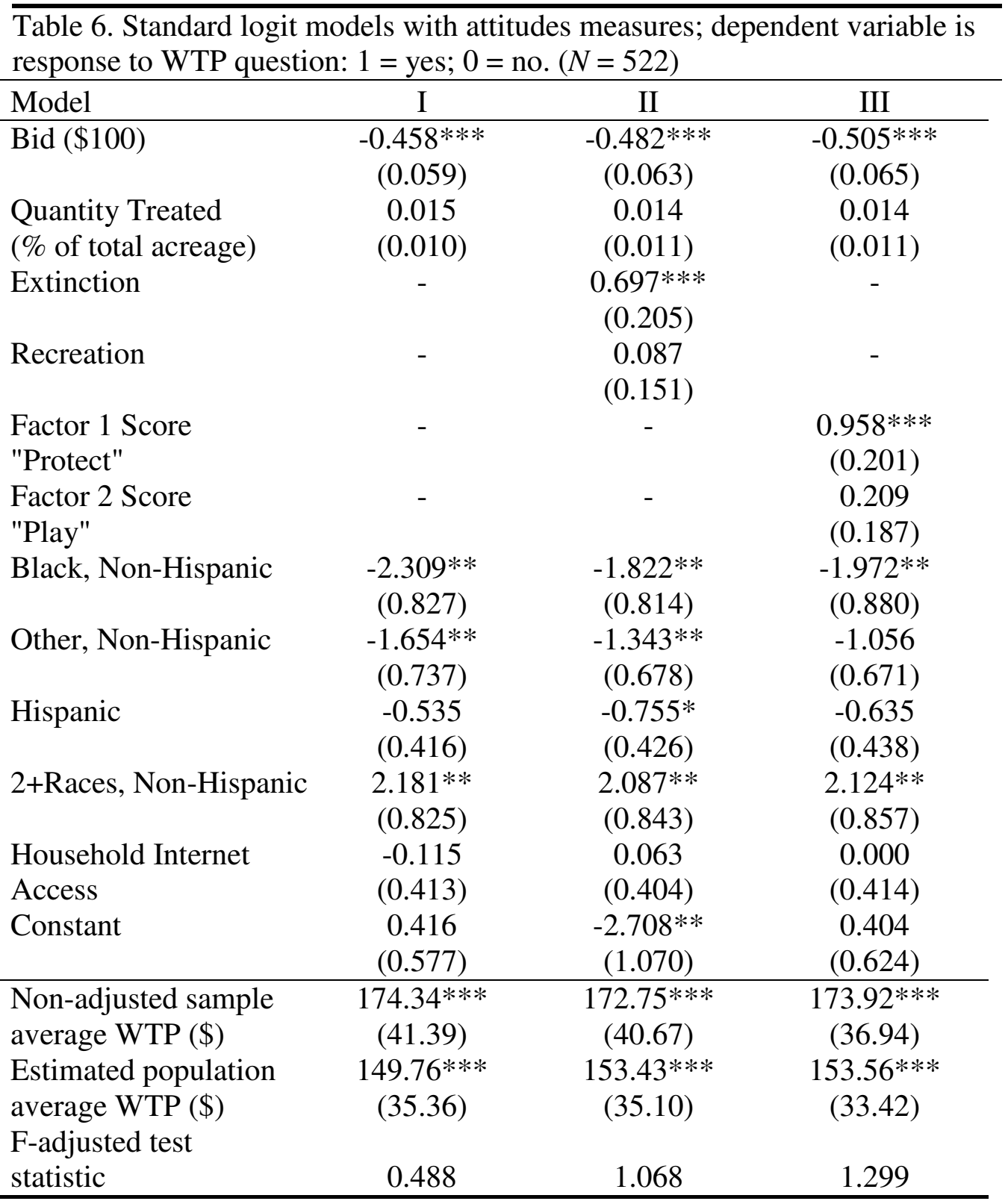

Notes: $* \mathrm{p}<0.10 ; * * 0.01>\mathrm{p}<0.05 ; * * * \mathrm{p}<0.01$. Standard errors in parentheses; Post-estimation standard errors are calculated via the delta method (Oehlert 1992). 
Table 7. Cluster analysis results, averaged over 1000 random initializations; dependent variable is response to WTP question: $1=$ yes; $0=$ no

Means of statistics and parameter estimates (standard errors)

\begin{tabular}{lccc}
\hline & $\begin{array}{c}\text { Cluster 1 } \\
\text { "Indifferent" }\end{array}$ & $\begin{array}{c}\text { Cluster 2 } \\
\text { "Protect" }\end{array}$ & $\begin{array}{c}\text { Cluster 3 } \\
\text { "Protect and Play" }\end{array}$ \\
\hline WTP Mean (\$) & -86.47 & 270.11 & 323.16 \\
& $(428.36)$ & $(92.04)$ & $(68.33)$ \\
WTP Std Error (\$) & 328.32 & 69.64 & 89.19 \\
& $(1015.92)$ & $(24.68)$ & $(39.52)$ \\
\hline Average Factor 1 Score & -0.77 & 0.45 & 0.67 \\
("Protect") & $(0.39)$ & $(0.52)$ & $(0.27)$ \\
Average Factor 2 Score ("Play") & -0.40 & -0.13 & 0.73 \\
& $(0.34)$ & $(0.47)$ & $(0.45)$ \\
N per cluster & 193.5 & 171.1 & 157.4 \\
& $(76.4)$ & $(59.9)$ & $(72.4)$ \\
\hline
\end{tabular}

Notes: Standard errors in parentheses are from Monte Carlo results; Post-estimation standard errors are calculated via the delta method (Oehlert 1992). 
Table 8. Cluster analysis and standard logit model for a "typical" set of three clusters; dependent variable is response to WTP question: $1=$ yes; $0=$ no

Statistics and parameter estimates (standard errors)

\begin{tabular}{|c|c|c|c|}
\hline & $\begin{array}{c}\text { Cluster 1 } \\
\text { "Indifferent" }\end{array}$ & $\begin{array}{l}\text { Cluster } 2 \\
\text { "Protect" }\end{array}$ & $\begin{array}{c}\text { Cluster } 3 \\
\text { "Protect and Play" }\end{array}$ \\
\hline \multicolumn{4}{|c|}{ Logit coefficient estimates (and standard errors), by cluster } \\
\hline $\operatorname{Bid}(\$ 100)$ & $\begin{array}{c}-0.454 * * \\
(0.157)\end{array}$ & $\begin{array}{c}-0.538 * * * \\
(0.100)\end{array}$ & $\begin{array}{c}-0.358 * * * \\
(0.072)\end{array}$ \\
\hline Constant & $\begin{array}{l}-0.335 \\
(0.427)\end{array}$ & $\begin{array}{c}1.670 * * * \\
(0.347)\end{array}$ & $\begin{array}{c}1.106 * * \\
(0.353)\end{array}$ \\
\hline \multicolumn{4}{|c|}{ Estimated willingness to pay (and standard errors), by cluster } \\
\hline WTP $(\$)$ & $\begin{array}{c}-73.68 \\
(112.19) \\
\end{array}$ & $\begin{array}{c}310.44 * * * \\
(56.76)\end{array}$ & $\begin{array}{c}309.08 * * * \\
(83.50)\end{array}$ \\
\hline $\mathrm{N}$ per cluster & 157 & 200 & 165 \\
\hline$\%$ per cluster & $30 \%$ & $38 \%$ & $32 \%$ \\
\hline \multicolumn{4}{|c|}{ Attitude measurements, by cluster } \\
\hline Factor 1 "Protect" & $\begin{array}{c}-1.00 * * * \\
(0.08)\end{array}$ & $\begin{array}{c}0.45 * * * \\
(0.07)\end{array}$ & $\begin{array}{c}0.67 * * * \\
(0.05)\end{array}$ \\
\hline Factor 2 "Play" & $\begin{array}{l}-0.16 \\
(0.14)\end{array}$ & $\begin{array}{c}-0.48 * * * \\
(0.08)\end{array}$ & $\begin{array}{c}0.91 * * * \\
(0.08)\end{array}$ \\
\hline Calinski/Harabasz & & & \\
\hline
\end{tabular}




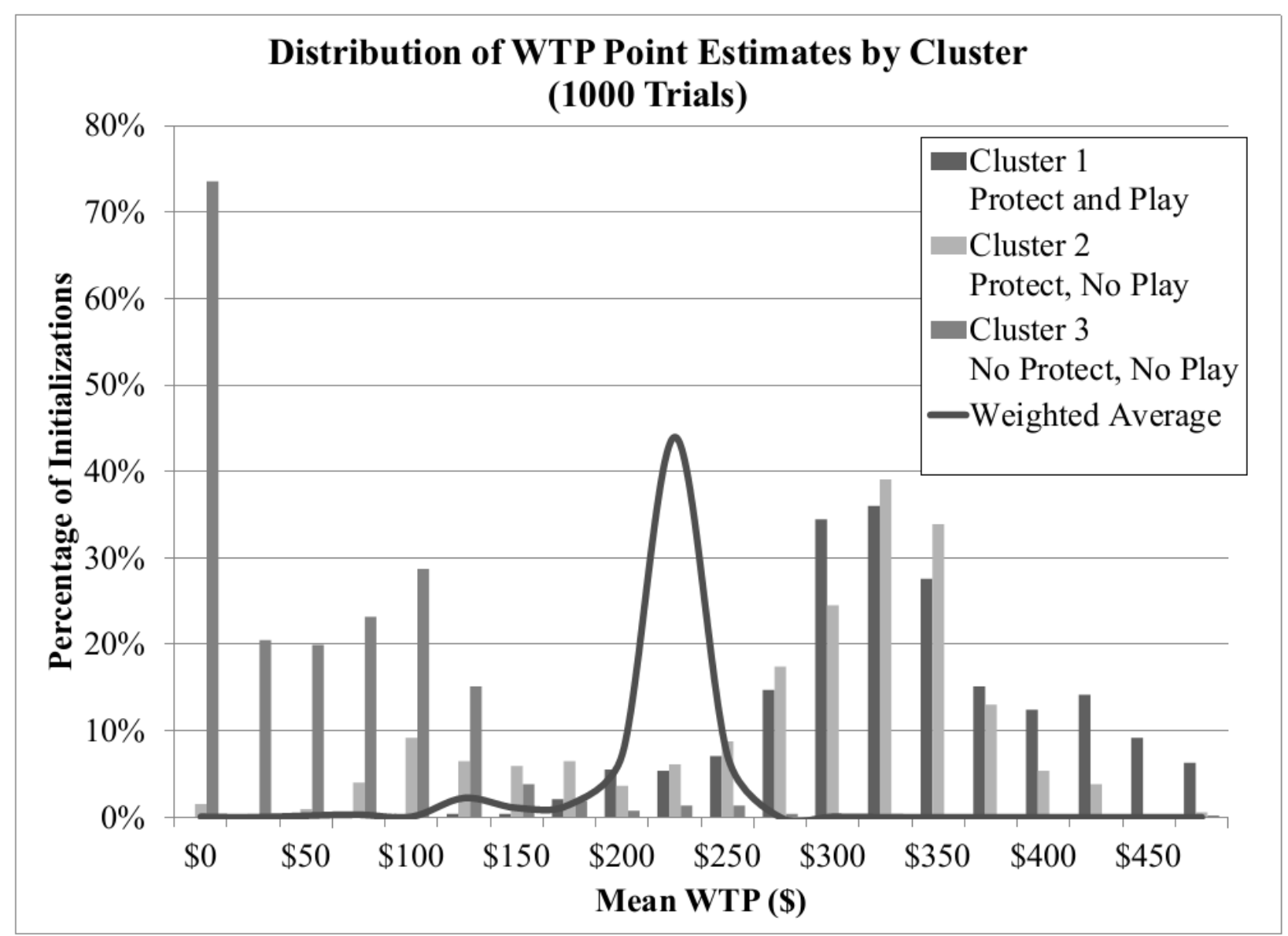

